\title{
Assessing Ecotoxicity of Size-fractionated Airborne Particulate Matter
}

\author{
Bettina Eck-Varanka ${ }^{1}$, Katalin Hubai ${ }^{1, *}$, Eszter Horváth ${ }^{1}$, Nora Kováts ${ }^{1}$, Gábor Teke ${ }^{1}$, and Ádám Tóth ${ }^{1}$ \\ ${ }^{1}$ University of Pannonia, Institute of Environmental Sciences, Veszprém, Hungary
}

\begin{abstract}
Particulate matter (PM) is grouped as coarse, fine, and ultrafine particles (UFPs) with aerodynamic diameters of 2.5 to $10 \mu \mathrm{m}$ (PM10), $<2.5 \mu \mathrm{m}$ (PM2.5), and $<0.1 \mu \mathrm{m}$ (PM0.1), respectively. The course and fine fractions have been well characterised from numerous aspects, including potential environmental hazard. However, more and more studies are targeted to the UFP fraction, as they bind relatively higher concentrations of potentially toxic materials and they might penetrate through cell biological barriers, posing higher risk to the biota. In our study, ecotoxic potential of size-fractionated urban aerosol was evaluated, using the kinetic version of the Vibrio fischeri bioluminescence inhibition bioassay. The kinetic protocol makes it possible to avoid false ecotoxicity readings which might appear in case of coloured and/or turbid samples. Our results showed that all PM fractions elucidated significant toxic response, highest toxicity was experienced in the range of $0.25 / 0.5 \mu \mathrm{m}$ and $0.5 / 1 \mu \mathrm{m}$ (with the EC 50s of 7.07 and $7.8 \%$ ). Ecotoxicity in general followed the typical pattern of number size distributions of submicron particles experienced in Europe.
\end{abstract}

\section{Introduction}

Particulate matter (PM) is grouped as coarse, fine, and ultrafine particles (UFPs) with aerodynamic diameters of 2.5 to $10 \mu \mathrm{m}$ (PM10), $<2.5 \mu \mathrm{m}$ (PM2.5), and $<0.1 \mu \mathrm{m}$ (PM0.1), respectively.

The PM2.5-10 fraction has been well characterised from numerous aspects, such as temporal (diurnal and/or seasonal) variations (e.g. [1-3]), origin [4], or composition (e.g. [5]).

The deleterious effect of the PM2.5-10 fraction on human health has been widely studied (e.g. [6]), also, there are data on the ecotoxic potential of this particulate matter fraction (reviewed by [7]).

It is generally agreed that smaller particles pose higher hazard as they bind relatively higher concentrations of potentially toxic materials and they might penetrate through cell biological barriers [8]. As such, more and more research are targeted to assess the environmental risk posed by these particles. However, while human health problems associated with UFP have been long studied (e.g. [9]) practically no information is available on what ecological risk this fraction might pose on the nonhuman biota.

In order to gain a preliminary view about the ecotoxicity profile of the different fractions, sizefractionated urban dust sample was analysed. For ecotoxicity assessment, the test based on the bioluminescence inhibition of the marine bacterium Vibrio fischeri was used. The species was recently renamed Alivibrio fischeri [10], however, as most standards still apply the $V$. fischeri name, it will be used hereinafter. This test is based on the inhibition of the
NAD(P)H:FMN oxidoreductase and luciferase enzyme system, which is reflected in the rapid decrease of light emittance of the bacterium. The reduction of light intensity is proportional to the strength of the toxicant, therefore it gives a reliable and easy-to-measure end point (Fig. 1.).

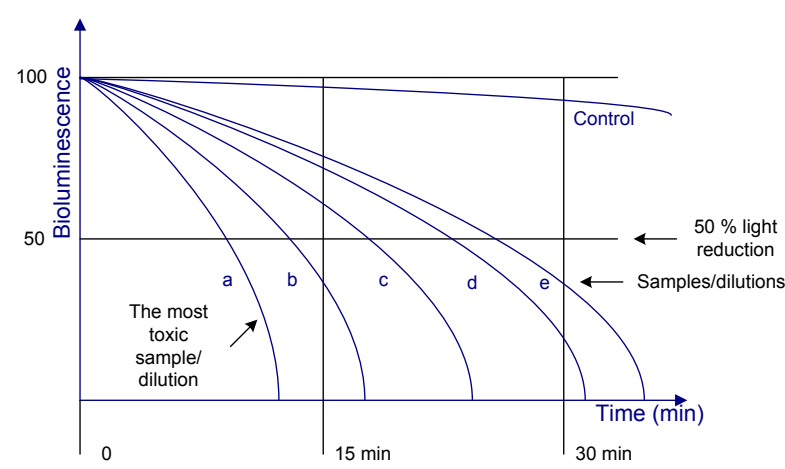

Figure 1. Luminescence inhibition is roughly proportional to the concentration of the toxic compound.

This bioassay was already used in the 1960's for assessing the deleterious effects of air pollutants [11, 12]. Recent studies involve, among others, urban dust (e.g. [13-15]), traffic-related emissions (e.g. [16, 17]) or fly ash (e.g. $[18,19])$. A detailed review is given by Kováts and Horváth, 2016 [20], including the application of genetically engineered bacterial strains.

In our laboratory, the Ascent Luminometer is used. This system is based on the kinetic version of the

\footnotetext{
*Corresponding author: hubai.katalin@mk.uni-pannon.hu
} 
bioassay, developed by Lappalainen et al. [21, 22]. Here, inhibition is calculated comparing the bioluminescence readings at the beginning and the end of the pre-set exposure, independently from the control. It is suitable to assess the ecotoxicity of solid and/or coloured samples, as false light output readings which might appear due to the physical effect of the presence of colour and/or suspended solids can be avoided. Accoring to our previous results, as dust samples are coloured and contain solid particles, this protocol provides the most reliable results, in comparison to non-kinetic protocols [23]. Light emittance is continuously recorded for the first $30 \mathrm{sec}$, as such, toxic effect can be immediately detected (Fig. 2).

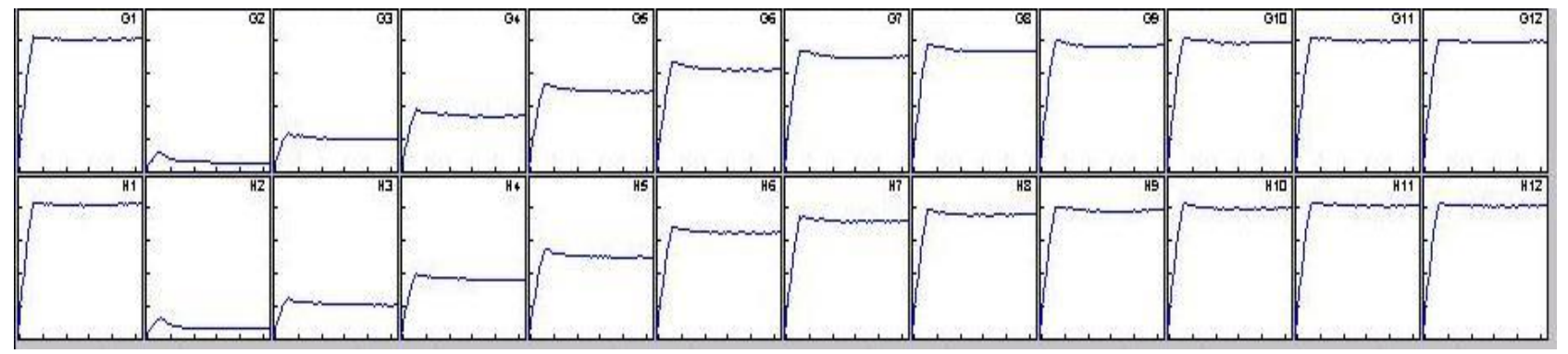

Fig. 2. Typical kinetic diagram of an aerosol sample. Light output is recorded in the first $30 \mathrm{sec}$ interval. As the sample contains solid particles, physical interference occurs, which reduces light luminescence reading: the peak is lower than in the control. After the peak, toxicity causes a rapid reduction in the light output while light output remains even in the control. The two rows show the two replicates. G1-H1 (left): control. G2-H2: highest, G12-H12: lowest concentrations.

\section{Materials and methods}

\subsection{Sampling, sample preparation}

Our sampling site was in transdanubian region of Hungary, in Veszprém (middle-sized city) in University campus $\left(47^{\circ} 05^{\prime} 14.7^{\prime \prime} \mathrm{N} 17^{\circ} 54^{\prime} 30.5^{\prime \prime} \mathrm{E}\right)$. Size-fractionated urban dust was collected using a Berner cascade impactor [24]. The impactor consists of eight stages (Table 1). Particulates were collected onto aluminium substrate. Sampling took place between 20.02. and 24.02, 2017. Each day, sampling was continued for 23 hours. For further analyses, a composite sample was used.

Effective area of the Berner foils (the area which actually contained particulates) was cut into small pieces and placed in a $4 \mathrm{ml}$ vial. Extraction was done by adding $3000 \mu \mathrm{L}$ DMSO and stirring in Vortex at $750 \mathrm{rpm}$. The extract was filtered $(0.45 \mu \mathrm{m}$ pore size $)$.

Table 1. The cutoffs of the Berner cascade impactor and the size of the collected particles.

\begin{tabular}{|c|c|c|c|}
\hline stage & $\begin{array}{c}\text { cutoff } \\
\text { (um) }\end{array}$ & $\begin{array}{c}\text { geometric } \\
\text { diameter }\end{array}$ & $\begin{array}{c}\text { collected particles } \\
\text { (range) }\end{array}$ \\
\hline 1 & 0.0625 & 0.088388348 & $0.0625-0.125$ \\
\hline 2 & 0.125 & 0.176776695 & $0.125-0.25$ \\
\hline 3 & 0.25 & 0.353553391 & $0.25-0.5$ \\
\hline 4 & 0.5 & 0.707106781 & $0.5-1$ \\
\hline 5 & 1 & 1.414213562 & $1-2$ \\
\hline 6 & 2 & 2.828427125 & $2-4$ \\
\hline 7 & 4 & 5.656854249 & $4-8$ \\
\hline 8 & 8 & 11.3137085 & $8-$ \\
\hline
\end{tabular}

\subsection{Ecotoxicity assessment}

Ecotoxicity tests were carried out following the protocol given by the ISO 21338:2010: Water quality - Kinetic determination of the inhibitory effects of sediment, other solids and coloured samples on the light emission of Vibrio fischer /kinetic luminescent bacteria test/. Shortly, the freeze-dried photobacteria were rehydrated with the reconstitution solution and stabilized at $15^{\circ} \mathrm{C}$ for 15 minutes before the measurement. After the sample was added to the bacterial suspension, bioluminescence intensity was continuously recorded for the first $30 \mathrm{sec}$. After the pre-set exposure time, $30 \mathrm{~min}$ in our case, luminescence intensity was read again. The light output of the unstressed bacteria was used as a reference for calculating the results.

EC50 and EC20 values were calculated from the light inhibition percentages by the Aboatox software provided with the Ascent Luminometer. The light inhibition (INH\%) was calculated based on the following equations:

$$
\mathrm{KF}=\frac{\mathrm{IC}_{30}}{\mathrm{IC}_{0}}
$$

and

$$
\mathrm{INH} \%=100-\frac{\mathrm{IT}_{30}}{{\mathrm{KF} \times \mathrm{IT}_{0}}_{0}} \times 100,
$$

where $\mathrm{KF}$ is the correction factor, $\mathrm{IC}_{0}$ and $\mathrm{IC}_{30}$ are the luminescence intensities of the control at the beginning and after $30 \mathrm{~min}, \mathrm{IT}_{0}$ and $\mathrm{IT}_{30}$ are the luminescence intensities of the sample at the beginning and after the 30 min contact time.

From the inhibition data of each concentration the software calculates Gamma using the equation below:

$$
\text { Gamma }=\frac{\mathrm{INH} \%}{100-\mathrm{INH} \%}
$$

\footnotetext{
* Corresponding author: hubai.katalin@mk.uni-pannon.hu
} 
and the inhibition what belongs to the Gamma $=1$ value gives the EC50.

\section{Results and Discussion}

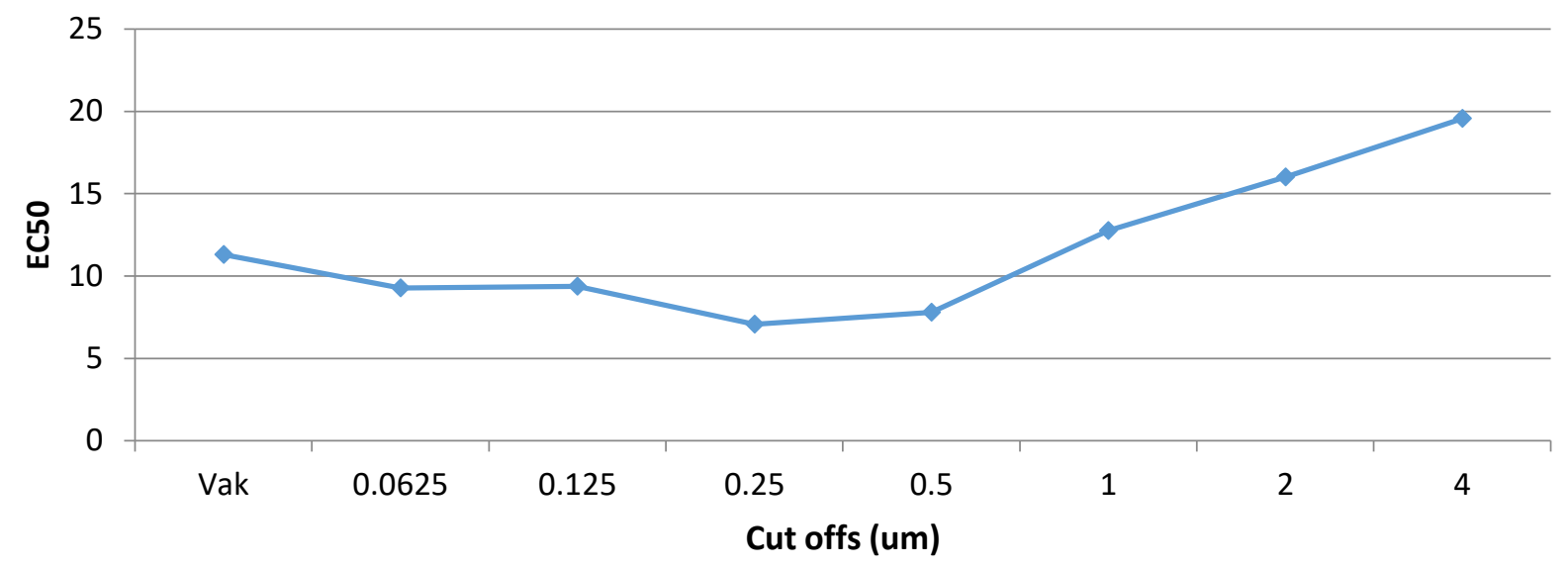

Figure 3. Ecotoxicity of the different particle size categories.

Results are expressed as EC50 (calculated concentration of the sample which causes $50 \%$ of toxic effect, in this case $50 \%$ of bioluminescence reduction). Please note, that the lower the EC50 value, the higher the toxicity.

Landkocz et al. (2017) demonstrated that UFP has greater cytotoxic and genotoxic potential than coarse particles [25]. In the study of Mesquita et al (2014), ecotoxicity of size fractionated aerosol samples was assessed on zebrafish embryos, using different endpoints: mortality and deformities. Results revealed that sub-micron fractions were mostly responsible for the toxic effects and putative toxic compounds, mainly PAHs, also concentrated in these fractions [26]. Valavanidis et al. (2006) also demonstrated that the fine particulate PAHs concentrations were higher than coarse particles. [27]

An important mechanism for causing toxic effect is the generation of reactive oxygen species (ROS). Studies have already established that reactive oxygen species have the ability to elucidate toxic response in Vibrio fischeri (e.g. [28]).

It can be concluded that while all PM fractions elucidated significant toxic response in the test bacterium $V$. fischeri, ecotoxicity in general followed the typical pattern of number size distributions of submicron particles experienced in Europe [29]. It should be noted, however, that the average number concentrations of ultrafine (10-100 nm) particles can be higher in extremely polluted areas (e.g. [30]).

Present study rather intends to give a methodological overview about sample preparation and ecotoxicity testing of size-fractionated dust. The kinetic version of the $V$. fischeri assay as described here is able to assess ecotoxicity from an extremely low quantity of sample, which makes it very useful in aerosol research. However,
Results clearly show that UFP has higher toxicity than coarse particles (PM1 and above). Highest toxicity was experienced in the range of $0.25 / 0.5 \mu \mathrm{m}$ and $0.5 / 1 \mu \mathrm{m}$ (with the EC50s of 7.07 and 7.8\%). However, it should be noted that all fractions elucidated significant ecotoxicity (Fig 3). in order to carry out comparative measurements (such as analytics), a more extended sampling campaign is required.

This work was supported by the BIONANO_GINOP-2.3.2-152016-00017 and EFOP-3.6.1-16-2016-00015 projects.

\section{References}

1. S. Hasheminassab, P. Pakbin, R.J. Delfino, J.J. Schauer, C. Sioutas, Environ. Pollut. 187, 1-9. (2014)

2. P.I. Jalava, Q. Wang, K. Kuuspalo, J. Ruusunen, L. Hao, Fang et al., Atmos. Environ. 120, 427-437. (2015)

3. T. Schilirò, S. Bonetta, L. Alessandria, V. Gianotti, E. Carraro,G. Gilli, Environ. Toxicol. Pharmacol. 39, 833-844. (2015)

4. Titos, G., Lyamani, H., Pandolfi, M., Alastuey, A. and Alados-Arboledas, L. Atmos. Environ. 89, 593602. (2014)

5. Schleicher, N.J., Schäfer, J., Blanc, G., Chen, Y., Chai, F., Cen, K. and Norra, S. Atmos. Environ. 109, 251-261. (2015)

6. F.R. Cassee, M.E. Heroux, M.E. Gerlofs-Nijland and F.J. Kelly, Inhal. Toxicol. 25, 802-812. (2013)

7. N. Kováts, A. Gelencsér, In: Hermans A. Air quality: Environmental indicators, monitoring and health implications. 99-130. (Nova Science Publishers, New York, 2013)

8. R. Chen, B. Hu, Y. Liu, J. Xu, G. Yang, D. Xu, C. Chen, Biochim. Biophys. Acta 1860(12), 2844-2855. (2016)

9. J. Schwartz, W. Douglas, D.W. Dockery, L.M. Neas, J Air Waste Manag Assoc. 46(10), 927-39. (1996) 
10. H. Urbanczyk, J. Ast, M.J. Higgins, J. Carson, P.V. Dunlap, Int. J. Syst. Evol. Microbiol. 57(12), 28232829. (2007)

11. W.F. Serat, F.E. Budinger Jr., P.K. Mueller, JB. 90, 832-833. (1965)

12. W.F: Serat, F.E. Budinger Jr., P.K. Mueller, Atmos. Environ. 1, 21-32. (1967)

13. W. Wang, C. Shi, Y. Yan, Y. Yang, B. Zhou, Ecotox. Environ. Safe. 133, 226-234 (2016)

14. S. Aammi, F. Karaca, M. Petek, Chemosphere 174, 490-498. (2017)

15. M. Pintér, N. Utry, T. Ajtai, G. Kiss-Albert, B. Jancsek-Turóczi, K. Imre, et al., Aerosol Air Qual. Res. 17, 1415-1426. (2017)

16. E. Vouitsis, L. Ntziachristos, P. Pistikopoulos, Z. Samaras, L. Chrysikou, C. Samara, et al., Environ. Pollut. 157, 2320-2327. (2009)

17. A.X.R. Corrêa, R.C. Testolin, M.M. Torres, S. Cotelle, J.J. Schwartz, M. Millet, C.M. Radetski, Environ. Sci. Pollut. Res. 24(10), 9399-9406. (2017)

18. S.C. Chang, Y.F. Wang, S.J. You, Y.M. Kuo, C.H. Tsai, L.C. Wang, P.Y. Hsu, Aerosol Air Qual. Res. 13, 1002-1008. (2013)

19. V. Silva, J.L. Pereira, I. Campos, J.J. Keizer, F. Gonçalves, N. Abrantes, Catena 135, 401-408. (2015)

20. N. Kováts, E. Horváth, Luminescence 31(4), 918923. (2016)

21. J. Lappalainen, R. Juvonen, K. Vaajasaari, M. Karp, Chemosphere 3, 1069-1083. (1999)

22. J. Lappalainen, R. Juvonen, J. Nurmi, M. Karp, Chemosphere 45, 635-641. (2001)

23. N. Kováts, A. Kovács, A. Ács, Á. Ferincz, B. Turóczy, A. Gelencsér, Toxicol. Pharmacol., 33, 284-287. (2012)

24. H.C. Wang, W. John, Aerosol Sci. Tech. 8, 157-172, (1988)

25. Y. Landkocz, F. Ledoux, V. André, F. Cazier, P. Genevray, D. Dewaele et al., Environ. Pollut. 21, 130-140. (2017)

26. S.R. Mesquita, B.L. van Drooge, C. Reche, L. Guimarães, J.O. Grimalt, C. Barata, B. Piña, Environ. Pollut. 184, 555-562. (2014)

27. A. Valavanidis, K. Fiotakis, T. Vlahogianni, E.B. Bakeas, S. Triantafillaki, V. Paraskevopoulou, M. Dassenakis, Chemosphere 65, 760-768. (2006)

28. W. Wang, J. Nykamp, X.D. Huang, K. Gerhardt, D.G. Dixon, B.M. Greenberg, Environ. Toxicol. Chem. 28(8), 1655-1662. (2009)

29. A. Asmi, A. Wiedensohler, P. Laj, A.M. Fjaeraa, K. Sellegri, W. Birmili et al., Atmos. Chem. Phys. 11, 5505-5538, (2011)

30. J. Gao, T. Wang, X. Zhou, W. Wu, W. Wang, Atmos. Environ. 43, 829-836 (2009) 